\title{
CORTAR EL NUDO. LOS RELATOS DE VIAJE DE MAIPINA DE LA BARRA, CLORINDA MATTO DE TURNER Y EDUARDA MANSILLA
}

\author{
Francesca Denegri \\ Pontificia Universidad Católica del Perú, Lima, Perú \\ adenegri@pucp.pe
}

\section{RESUMEN / ABSTRACT}

Este artículo analiza los relatos de viaje de Maipina de la Barra (1878), Eduarda Mansilla (1882) y Clorinda Matto de Turner (1902) a partir de la figura de la huida como problemático nudo gordiano que deja en la escritura visibles marcas e inflexiones de género sexual. Propone que el tema de "la herida", ocasionado en De la Barra por la pobreza y el abandono, en Matto por la violencia del trabajo negado, la propiedad destruida y la voz censurada y en Mansilla por la obligada elección entre familia y vocación se moviliza en estas narrativas a partir de diversas estrategias que incluyen su esencialización, su historización o su silenciamiento.

PALABRAS CLAVE: narrativas de viaje, violencia de género, siglo XIX, memoria y emociones.

\section{Cutting the knot. The Travel Literature of Maipina de la Barra, Clorinda Matto de Turner} Y EDUARDA MANSILLA

This article analyses the travel narratives of Maipina de la Barra (1878), Eduarda Mansilla (1882) and Clorinda Matto de Turner (1902), considering the concept of escape as a problematic Gordian knot which leaves evident gender marks and inflections in the writing. It proposes that the subject of the wound, provoked in De la Barra by impoverishment and neglect; in Matto by the violence of work denied, destroyed property, and the censored voice; and in Mansilla by the compulsory choice between family and vocation, is developed in these narratives through diverse strategies which include its over-investment, historization and silencing.

KEYWORDS: Travel narratives, gender violence, Nineteenth century, memory and emotion. 
Cuenta la leyenda que ante la imposibilidad de desatar el nudo de Gordias, Alejandro resolvió sin contemplaciones cortarlo de un solo tajo con su espada, salvando con esta sencilla operación el desafío que el nudo representaba. Este artículo ubica algunos relatos de viajes de las mujeres del XIX en el punto ciego de la leyenda, que es el configurado por la diferencia de género. Si bien es cierto que frente a situaciones de conflicto personal profundamente complejas y difíciles de desatar, ellas optaron por el viaje sin retorno como única forma posible de ponerse a resguardo, este corte no fue ni rápido ni sencillo, antes bien implicó serias pérdidas personales además de un giro drástico en sus vidas. El viaje en esta lectura que propongo en clave femenina significa el doloroso pero necesario abandono de la patria o de la familia como intento de huir de la violencia y de las amenazas físicas o simbólicas que se ciernen contra las escritoras. El nudo que ellas en efecto cortan cuando optan por emprender el viaje es pues bastante más complejo que el de Gordias en la medida en que el corte significa un giro extremo en sus vidas que por añadidura no resolvería el problema, solo lo postergaría. La deuda incurrida en el acto mismo de cortar es irreversible en la medida en que tras la partida no podrán volver a establecerse en la patria amada, o volver a armar la familia desarmada que resultó como producto del viaje. Queda claro que desatarlo habría sido su deseo y que en encontrar la fórmula para lograrlo habrían invertido hartas disquisiciones, marchas y contramarchas, pero que conscientes de las frágiles componendas implicadas en el acto de desatarlo, optaron por cortarlo. Propongo pensar en el nudo gordiano como metáfora de la diferencia de género en el viaje decimonónico y en la desigualdad de condiciones con que hombres y mujeres tejen los hilos públicos y privados con los que configuran el diseño de sus libros de viaje y de vida.

Mi enfoque en estas páginas son los relatos de tres viajeras latinoamericanas en el último tercio del siglo XIX. Ellos son Mis impresiones y mis vicisitudes en mi viaje a Europa pasando por el Estrecho de Magallanes y en mi excursión a Buenos Aires pasando por la Cordillera, de la chilena Maipina de la Barra (Buenos Aires, 1878); Recuerdos de viaje, de la argentina Eduarda Mansilla (Buenos Aires, 1882); y Boreales, Miniaturas y Porcelanas, de la peruana Clorinda Matto de Turner (Buenos Aires, 1902). Me interesa identificar, a partir de la figura del nudo gordiano y de la huida, las marcas y las inflexiones visibles de género sexual en estos libros de viajes de autoría femenina que se escriben en una época en que dicho género literario gozó de gran popularidad y prestigio en América Latina por razones que otros críticos como Montaldo (1994), Pratt (1996) y González Echevarría (2000) han explorado ampliamente y que no es mi objetivo elaborar en este espacio. 
Fueron muchos los escritores varones de la región que como Sarmiento escribieron sus testimonios de viajes "al revés" (Montaldo 66). No solo por tratarse de una mirada de viajeros latinoamericanos en Europa y ya no la de viajeros europeos que vienen a identificar territorios "nuevos" en América, sino también porque cuando los escritores sudamericanos abordaban sus transatlánticos en Valparaíso, Buenos Aires o El Callao era como si estuvieran regresando a un continente que ya conocían aun si solo desde sus sillones de lectura y gracias a la gran biblioteca europea que tenían a la mano (73). Pero también porque eran viajes que el escritor emprendía para legitimar su lugar de enunciación trasatlántico, prestigioso y público que a su regreso le permitiera afianzar su pertenencia a las estirpes de "grandes hombres de la patria". En la mayoría de los casos, los escritores dentro de esta tradición viajan con misiones de Estado muy claras, ya sea en representación diplomática, como son los casos conocidos de los chilenos Vicuña Mackenna a Nueva York, Blest Gana a Washington, Paris y Londres, el argentino Miguel Cané en Venezuela y Colombia, o como el del peruano José Arnaldo Márquez en San Francisco. Viajan también en misión oficial de estudio e importación de conocimiento, como es el conspicuo caso del viaje de Sarmiento a Estados Unidos para evaluar los sistemas públicos de instrucción y su posterior implementación en Chile, o en representación cultural del país natal como fue el viaje de Palma a España para las celebraciones del cuarto centenario del descubrimiento y de Blest Gana a México en representación de Chile en el Congreso Panamericano de 1901. Otra misión de viaje era la de representación de intereses comerciales, como fue el caso del viaje de Lucio Mansilla a la India como agente de los negocios de su padre. Todos estos sin mencionar los viajes de formación, como el de Vicente Pérez Rosales y otra vez Blest Gana, quienes van a Paris para completar su educación, o de turismo como el del chileno Lizardi en España, el de los peruanos Juan Bustamante y Juan de Arona, o Eduardo Wilde y Lucio Vicente López en Europa. Finalmente no hay que olvidar los viajes de aventura como el que hiciera Pérez Rosales a California en busca de oro, Lucio Mansilla a las tolderías ranqueles y Vicuña Mackenna al interior de su país. Es importante referirse a este largo catálogo de relatos de viaje de autoría masculina porque se trata sin excepción de viajes realizados con itinerario y propósitos determinados no obstante la diversidad de objetivos y acaso la posterior desviación de alguno de ellos. Lo que me interesa subrayar es que en estos textos clásicos el "para qué" del viaje está claramente articulado a la pertenencia privilegiada del viajero a la nación, y a la adquisición y acumulación de capital cultural en las culturas 
metropolitanas como herramientas fundamentales de poder que sus autores han de saber exhibir y usar eficazmente a su regreso en aras del fortalecimiento de su figura de hombres públicos.

En contraste con este panorama, lo que salta a la vista en la lectura de los libros de viaje de autoría femenina, como espero demostrarlo en este artículo, es que ninguno de estos viajes se realiza por encargo oficial o porque las viajeras aspiren a regresar habiendo alcanzado la gloria, el poder o el barniz del saber europeo, sino por problemas personales irresueltos en sus países de origen o de residencia que las conminan a partir en viajes sin boleto de retorno y en una suerte de huida necesaria para resguardarse del castigo o de la amenaza de fracaso, ya sea matrimonial, social o vocacional, o más exactamente, de su proyecto de vida. Si bien las razones de la partida son tan claras y urgentes como lo es la supervivencia, el itinerario a seguir y la agenda de llegada aparecen en mayor o menor grado suspendidos en una nebulosa. Por añadidura, si en el caso de los varones el viaje se hace con un pasaje de vuelta que es tanto o más necesario que el de la ida, el de las viajeras se hará solo con un pasaje de ida. De hecho, Maipina de la Barra y Clorinda Matto partirán de Chile y Perú, respectivamente, para no regresar más a vivir en su tierra natal, excepto eventualmente de visita, como en el caso de Maipina; y Eduarda Mansilla partirá del hogar que comparte con su familia en Paris para no volver hasta después de seis años y también de visita. Mientras que los viajeros volverán a su puerto de partida para ser bien recibidos y retomar la vida nacional engrandecidos por la experiencia y listos para asumir nuevos cargos públicos -una curul en el parlamento, una nueva embajada o consulado, una gobernación -que los acerquen cada vez más a la figura ambicionada de "padre de la patria", las viajeras morirán en el extranjero o en el caso de Mansilla, de vuelta en su patria pero tan alejada de los blasones y condecoraciones públicas que pedirá que junto a ella desaparezca también toda su obra. En el caso de otros viajeros, como Palma y Blest Gana, viajes y cargos serán los hilos intermitentes y consecutivos con los que tejerán una vida de éxitos y reconocimientos continuos. Para concluir con los contrastes entre unos y otros, solo señalar que mientras que la escritura del viaje masculino produce diversas formas de alarde en el texto, aquella del viaje en clave femenina produce antes bien, como veremos, diversas estrategias de representación fantasmática, y en algunos casos de silenciamiento del conflicto que las compelió a emprender el viaje de partida.

Por alarde me refiero a cierto tipo de exhibicionismo o inclinación a exhibir ante el público lector conductas que transgreden los códigos aceptados de 
sociabilidad de clase y género. Los ejemplos más conspicuos son los alardes de omnipotencia e "incorregibilidad" acosadora de la que hace gala especialmente Lucio Mansilla, pero también José Arnaldo Márquez y Vicente Pérez Rosales, como estrategias narrativas a la que echan mano para construir autorretratos de acendrada virilidad ${ }^{1}$. En el caso de Mansilla, los alardes de voyerismo con los que sostiene en las Causeries su aura de dandy excéntrico y blasé llegan al paroxismo en "Catherine Necrasoff", en la que se exhibe como seductor irresistible; en "Limosna y mendicidad", en el que detalla alegremente su costumbre de inspeccionar los cuerpos de las mujeres que caminan por la calle y perseguirlas hasta sus casas aprovechando de su distracción (427-428); y "En las Pirámides de Egipto", donde alardea haber comprado una mujer en un mercado de mujeres lleno de abisinias, nubianas y georgianas desnudas (105) . Los alardes sin embargo no solo son de naturaleza erótica, también abundan aquellos de cosmopolitanismo, como los que se registran en el relato de Blest Gana con respecto al provincialismo de los norteamericanos en sus viajes de turismo al Niágara; y los alardes literarios como los que despliega Palma cuando se complace en describir en sus Recuerdos de España las amistades que cultiva con grandes escritores como Zorrilla, Valera, Castelar, Campoamor y Pardo Bazán, y los de Sarmiento cuando registra sus contactos con personajes de primera fila en la cultura y política europeas.

El común denominador de los relatos de De la Barra, Mansilla y Matto en cambio, es la presencia de una herida que deben saber orillar o manejar en el tejido mismo de la narración. Llama la atención que a pesar de la singularidad en tono, sensibilidad y lenguaje que distingue a cada uno de estos textos, y a pesar de la particularidad histórica que los produce, aparezcan en los tres casos esta figura de la huida que hace visible las inflexiones de género sexual con las que es necesario conjugar el género literario de viajes. Opto por estos tres textos en mi recorte, pero me queda claro que hubiera podido incluir otros de viajeras que también tuvieron que cortar el nudo que las asediaba y

Es notoria, por ejemplo, en Recuerdos de viajes a los Estados Unidos del Norte la autorrepresentación reiterada que despliega Márquez en los capítulos iniciales de su relato como un don Juan que objetiviza alegremente el cuerpo de sus compañeras de travesía, a quienes describe una y otra vez como "lindas mujeres" que aunque tuvieran novio, parecían “ávidas de placeres" (9). En Diario de un viaje a California vale la pena señalar asimismo la evocación a antiguas amantes que repudiaron al sujeto narrador por pobre, llámense Panchita, Amalia, Cunigunda o Rosa, y que ahora tendrían que reconocerlo como hombre rico, fantasía que lo deleita $(24,28,38)$. 
asumir las consecuencias. Entre ellas, Flora Tristán, quien viaja al Perú desde Francia huyendo de un esposo violento y de una legislación francesa que condenaba como delito la separación conyugal, con la esperanza de reclamar una herencia con la que pudiera vivir independientemente, y que fruto de este viaje publica Peregrinaciones de una paria; y Juana Manuela Gorriti, quien huye de su esposo en La Paz con sus dos hijas pequeñas luego de un conflicto conyugal del que tenemos poca información, cuyo fruto es un relato de viaje ficcionalizado, Peregrinaciones de un alma triste.

\section{LA ESENCIALIZACIÓN DE LA HERIDA. MIS IMPRESIONES Y MIS VICISITUDES, DE MAIPINA DE LA BARRA}

Maipina de la Barra huye en mayo de 1873 de Valparaíso rumbo a Europa por encontrarse, tal como lo consigna en el párrafo inaugural de su relato, "viuda, con solo una hija de 16 años de edad por compañera, aislada, casi olvidada, y entregada a la contemplación de un triste presente y de un nebuloso porvenir, cuyo dolor aumentaba la memoria de mi antigua posición" (13). Atenazada, además, por una situación económica precaria y en progresiva decadencia a la que ella enfrentaba con el único recurso que tenía entonces a la mano, dando clases particulares de piano y canto. Como es sabido, el trabajo femenino a lo largo del siglo XIX no fue considerado como opción digna ni aceptable para las mujeres de élite, por lo que sentiría malestar al verse "obligada por las vicisitudes de mi familia a trabajar para ocurrir a las necesidades de la vida" (13). La figura de la huida se configura pues desde el inicio, como tópico central de Mis impresiones, y en la segunda parte, Mis vicisitudes esta adquiere visos de leitmotiv que atraviesa y estructurara el relato ${ }^{2}$. Cuenta la narradora que tuvo que preparar el viaje con sigilo y disimulo, recurriendo incluso a la mentira acerca de su plan porque temía que la retuvieran, y lo que ella de verdad quería, era irse para "no volver más"

\footnotetext{
Siguiendo la nomenclatura de Ulloa (2003), en este artículo optaremos por referirnos a Mis impresiones para la primera parte que describe la partida de Maipina con su hija desde Valparaíso en 1873, y que incluye la travesía hasta Burdeos, su estancia en Francia e Italia, el viaje de retorno y su llegada de vuelta a Valparaíso un año después, en 1874. Mis vicisitudes incluye su estancia en Valparaíso donde seguirá dando clases, el relato del distanciamiento con su hija por el matrimonio con un joven que ella desaprueba, y su partida definitiva de Chile, esta vez a Argentina, a través de la cordillera.
} 
(16). A su regreso del periplo europeo, un año más tarde, y tras el conflicto que le supone la opción de matrimonio de su única hija, al que ella se opone vehementemente, vuelve a partir "sin conocer bien el término de mi viaje, sin mas objeto que huir de mi desventura." (206). A pesar de que se siente debilitada de salud, resuelve entonces "contra la opinión de los facultativos" (104), como lo hiciera también la narradora de Peregrinaciones de un alma triste, organizar rápidamente otra vez sus asuntos y volver a huir, aunque esta vez en condiciones mucho más duras que las de su viaje a Europa, porque ahora debe cruzar la cordillera ella sola, sin hoja de ruta, sin destino final claro y a lomo de mula ${ }^{3}$. Al final del primer tramo, en Santa Rosa de los Andes, enferma otra vez, desobedece nuevamente la opinión del médico (195), razón por la cual se debate en la duda agónica de si desistir o seguir "a riesgo de perecer en el camino" (194). La duda la traspasa, “¿Que iba yo a hacer en otras partes? ¿Me iría bien?”, se pregunta, para luego responder con amargura que si su "vida entera ha sido un tejido de desventuras, un martirio prolongado; ¿cómo podría ser ahora diferente?" (203). Finalmente, después de detenerse en Mendoza y Rosario, llega a Buenos Aires donde se instalará hasta su muerte en 1904. El tópico del infortunio es recogido por los editores en la Advertencia cuando anuncian a sus lectoras que entre las páginas del libro que tienen entre manos podrán enterarse de "las impresiones de viaje de la autora, y de una de las mayores amarguras acaecídole al regresar a Chile, su patria" $(3)^{4}$.

Los significantes que atraviesan este relato de viajes -"abnegación", "agonía", "angustia", "abatimiento", "desgracia", "quebrantamiento", "desamparo", "dolor", “desesperación”, "desfallecimiento”, “desventura”, "pesar", "enfermedad", "sacrificio", "quebranto", "resignación", "rendimiento"

3 Los relatos de Gorriti y De la Barra son contemporáneos, publicándose el primero apenas dos años antes que el De la Barra, también en Buenos Aires. En ambos casos, las viajeras están enfermas y parten desobedeciendo las órdenes de sus médicos y contraviniendo los deseos de sus familiares. Asimismo, comparten la incertidumbre de su destino final. De la Barra anuncia primero su plan de dirigirse a Mendoza, pero luego sigue camino a Rosario, y finalmente a Buenos Aires. Laura, el personaje del relato de ficción de Gorriti, se embarca en El Callao con el único objetivo de alejarse de Lima, y con destino incierto.

Los acentos de mi lectura no coinciden siempre con aquellos de otras estudiosas de este relato (Arcos y Salomone (2014), y Ulloa (2012)), quienes optan por no subrayar el hecho de que Maipina no regrese más a vivir en Chile, y privilegian el deseo de la escritora de ofrecerle a su hija la oportunidad del Grand Tour europeo como motivación del viaje en Mis impresiones, y el disgusto posterior por el matrimonio de su hija en Mis vicisitudes. 
y "martirio" entre tantos otros- se constelan alrededor del campo semántico del sufrimiento mariano, tópico que comparte con los textos de Gorriti y Tristán y que configuran una retórica de las lágrimas en la misma línea que propone Ana Peluffo para Aves sin nido de Clorinda Matto y Sab de Gertrudis Gómez de Avellaneda. Sin embargo, tratándose de un relato de viajes y no de una novela, dicha retórica se despliega con el fin de representar el desamparo e impotencia de un sujeto narrativo cuyo único deseo posible en esas circunstancias es la sobrevivencia. Una sobrevivencia propia del sujeto femenino que se diferencia del masculino clásico de las "literaturas de sobrevivencia" que describe Pratt para relatos como Robinson Crusoe, repletos del motivo del peligro, ya sea por naufragio, motín o cautiverio que el héroe deberá sortear. Los peligros que se le presentan a esta narradora formada en la devoción religiosa y en el culto a la familia y al espacio doméstico son de orden más complejo, porque no solo se trata de invocar el coraje para bordear un abismo o atravesar un río torrentoso en la cordillera, sino sobre todo, para evitar el naufragio ahogada en su propio miedo, o el cautiverio interno que supone el sufrimiento y la soledad como modo de vida. Como anota la narradora, el miedo la paraliza y la deja "como insensible", como "solo el reo a quien notifican la última pena podría comprender" (197). La resignación y la fe como únicas armas en estas circunstancias parecen tan ineficaces como las del Quijote en su lucha contra los molinos de viento. Pero a ellas echa mano, entre ayes y gemidos, encomendando su sufrimiento una y otra vez a una voz "íntima" que la conmina a confiar en la Providencia salvadora (206). Empero, a medida que el diálogo con esta otra voz la aferra a la esperanza de la salvación, crecerá en ella el convencimiento de una "gran debilidad" propia que la conmina a obedecer esa voz secreta como misión y destino de vida $(201,207)$.

Se trata de un sufrimiento que la acompaña permanentemente e intensifica su vulnerabilidad ante circunstancias que, desde una mirada mariana, tornan incierto su futuro y doloroso el presente, configurándola como víctima de su propio destino 5 . En La política cultural de las emociones, Sarah Ahmed

\footnotetext{
La mirada "mariana" que sugiero es derivativa del concepto de "marianismo" como reverso del machismo, elaborado por Evelyn Stevens (1973). Propone Stevens que en las culturas mestizas latinoamericanas después de la conquista se fue sedimentando una figura normativa de la mujer como encarnación de la superioridad moral y espiritual que evoca para los católicos la Virgen María al pie de la cruz. Se trataría de una fuerza sobrenatural propia de las mujeres que engendra en ellas la abnegación, la humildad, la capacidad infinita de
} 
escribe acerca de los peligros de que en medio de su dolor, el sujeto extirpe la herida que lo perturba de la especificidad de su historia, de esa historia, $\mathrm{y}$ de esas causas sociales que fueron las que infligieron la herida que ahora duele. El peligro, señala Ahmed, está en caer en la tentación de fetichizar el dolor, es decir, de pensarse a una misma como una gran herida, de esencializarse como esa gran herida, en lugar de pensarse como alguien que fue herido en algún momento y en alguna circunstancia precisa del pasado (32-33). Al identificarse con la herida y el sufrimiento de la herida, es decir, al confundir la herida con la identidad, Maipina arriesga borrar la historicidad y el origen social de su dolor, el mismo que podría identificarse como la negativa de la sociedad a reconocer el derecho de las mujeres de todas las clases al trabajo y a la autonomía. La pobreza tiene rostro de mujer, como ya lo había descubierto Flora Tristán en sus Peregrinaciones de una paria, o en términos más modernos, la pobreza es femenina ${ }^{6}$. Carla Ulloa señala que el reclamo clave del libro es la expulsión de las mujeres en su sociedad de origen del mundo del trabajo, y la validación de las nociones de superioridad europea por el estatus de las mujeres en ese continente (Ulloa 2013, 26). Aun si el sujeto narrativo reclama en diversas partes del relato el derecho de las mujeres al trabajo negado en su país, y se lamenta por la mirada clasista y patriarcalista que lo deshonra, sorprende que no llegue a conectar esta división del trabajo, propia de las sociedades patriarcales, con su propia situación de viuda pobre y con su propia identidad de víctima. En su lugar, asistimos en el decurso del relato, al desplazamiento de la agencia personal del sujeto por una "fuerza providencial" que desde algún lugar la ampara, pero de la que ella apenas tiene control.

$\mathrm{Al}$ abanico de adjetivos y sustantivos relativos al sufrimiento físico y moral, al énfasis de su maternidad solitaria y de su viudez desamparada, se sumará la figura del Dios Padre que le habla legitimando su posición mariana doliente

sacrificio, y la paciencia a todo trance ante los sufrimientos de la vida y ante los desplantes de los hombres (Stevens 1973). Cabe señalar además que a partir de la proclamación por el papa Pío IX en 1854 del Dogma de la Inmaculada Concepción, la cultura marianista en América Latina se vio fortalecida y legitimada. No está demás recordar que el dogma habrá permeado la cultura de las familias católicas de elite chilena en la que Maipina de la Barra se formó.

En 1978, Diana Pearce acuño la idea de la feminización de la pobreza, después de investigar las condiciones y características particulares de los pobres en Estados Unidos, y concluir que dos tercios de los pobres de su país eran mujeres. La relación entre la desigualdad económica y la desigualdad de género sigue siendo una constante en nuestros días. 
y ennoblecedora, y configura con su voz un hilo conductor que se suma a los otros para intensificar y apretar el diseño del tejido. El problema con la fetichización es que al volverse estático el dolor en la subjetividad de quien lo sufre, la experiencia traumática se naturaliza. El dolor entonces pasa a ser fundador de una identidad que se concibe a sí misma como sujeta al evento, en lugar de ser sujeto del evento 7 . A pesar de describir el desplazamiento de la viajera en el tiempo y en el espacio, el tiempo en Mis impresiones no solo parece detenido sino que, al haber quedado la herida extirpada de su historia, esta aparece suspendida en un vacío social y al margen de la comunidad de origen. El dolor de la viudez, la enfermedad y la pobreza permea el texto de tal manera que queda poco espacio para otro mandato que pudiera servir de contrapeso al de "débil mujer" y angustiada madre. La agencia histórica del sujeto narrador amenaza reiteradamente con desaparecer en este proceso de inexorable desubjetivación frente a los episodios propios del viaje, proceso que adquiere mayor densidad con el desdoblamiento de la voz narradora en otra voz que le habla desde el más allá. Se trata de una voz que cruza el texto de principio a fin para aconsejarla, tranquilizarla y profetizar su destino. Esta voz, identificada como la Madre Dolorosa/Providencia, le habla desde el primer capítulo, en momentos de confusión grave y paralizante para la narradora, en una iglesia de Santiago, adonde ella ha ido a rogarle que la ilumine, y la conmina a emprender el viaje de partida. "Ella me escuchó", escribe. "Al salir de la Iglesia iba decidida a realizar mi viaje a Europa... $\mathrm{y}$ al ir a ponérselo en conocimiento de mi hija ella se adelantó diciéndome: "Mamá: debemos irnos a Europa porque Jesús y la Virgen me lo han inspirado en la iglesia. ¿Qué podía yo responder a esta sorpresa?” (De la Barra 16). La sorpresa es, claro, que madre e hija hayan escuchado el mismo consejo al mismo tiempo. Con la aparición de esta voz, la suerte está echada para el sujeto narrador y solo le queda organizar su viaje en secreto.

Paradójicamente, y a pesar de su posicionamiento dentro del marianismo establecido, la autora encuadra su relato en la sutil denuncia de este mismo discurso. Escribe en su "Dedicatoria a las damas argentinas": "Al hacer este trabajo tan solo me propongo fomentar el desarrollo de elevadas ideas que muchas de nuestro sexo guardan ocultas en el fondo de su pecho y a las cuales

Debo la identificación de esta distinción entre ser "sujeto de" y "sujeto a" a la reflexión que hace Carolina Alzate acerca de los discursos que se tejen sobre la mujer en el contexto de la producción literaria de Soledad Acosta de Samper (Alzate 27). 
no dan expansión tal vez por un falso temor a la pública crítica, dejando así de manifestar los dones con que la Providencia nos ha dotado" (11). A este sutil lance de guante con el que anima a sus lectoras a liberar y potenciar sus dones reprimidos por el temor a la crítica, se le da otra vuelta de tuerca cuando parece aludir al modelo femenino de abnegación mariana como si este estuviera condenado a pasar pronto a su forma residual en un mundo en el que las demandas de educación y trabajo de las mujeres hacían más y más ruido. Termina así su dedicatoria lamentándose de que "no conozcamos bien lo que perdemos [al] contrariar nuestras bellas inclinaciones" (11). No estaría fuera de orden sospechar que en la escritura de su experiencia de viaje, Maipina efectivamente "descubre lo que perdió" (la agencia), y que como resultado, al final de este proceso opta por asumir la posibilidad de ser "sujeto de" y no solo "sujeto a". Podríamos concluir entonces, como apunta Carla Ulloa, que el viaje parece haberla transformado (Ulloa, 2102). De hecho, una vez establecida en Buenos Aires, se dedicará a investigar, a seguir viajando y a dar conferencias públicas sobre la educación para las mujeres, además de ofrecer recitales musicales y practicar el espiritismo, con lo que asumimos que el modelo femenino de sufrimiento mariano, gracias al alejamiento de su patria, llega a ser desplazado por uno renovado de agencia y trabajo propios de la modernidad. El discurso mariano y fetichizante de la herida propuesto en este artículo se confrontaría entonces, a manera de contrapunto, con el discurso pedagógico que ha sido examinado en otros estudios anteriores a este (Ulloa 2012, 2013 y Arcos y Salomone 2014). Como sostienen estas críticas, no se puede soslayar la apuesta pedagógica resumida en el programa de educación que presenta la autora en su totalidad en el capítulo XVIII, y que aspira a una educación integral moral y práctica, que logre capacitar a las mujeres como profesionales, de modo que no puedan "volver jamás a ser pequeñas" (De la Barra 172). Propongo como reflexión final pensar el libro como un proyecto de bisagra entre dos generaciones, la de la autora, que se ve a sí misma por las razones propuestas hasta aquí, en riesgo permanente de "volver a ser pequeña" y la generación de su nieta, quien se habría visto favorecida por un programa educativo que, como lo proponía Maipina, autonomice y des-tutelice a las mujeres. Aunque su hija Eva, causante de la segunda huida descrita en Mis vicisitudes no se beneficiaría directamente del programa de educación que ofrece su madre a las lectoras argentinas y chilenas de su libro, ella aparece ya, en su resistencia contra viento y marea a los deseos de la madre y en su sólida afirmación en el derecho a elegir esposo, como una figura femenina moderna. Todo lo cual nos sugiere que 
Blanca Lila Encarnación, hija de Eva y nieta de Maipina, mencionada en la carta que la autora incluye en el apéndice de su libro, representaría esta nueva generación de mujeres depositaria de las lecciones de sus abuelas.

\section{LA HISTORIZACIÓN DE LA HERIDA. “BOREALES”, DE CLORINDA MATTO DE TURNER}

Clorinda huye de Lima el 25 de abril de 1895 porque su casa y su imprenta han sido saqueadas, su hermano tomado de rehén, y ella perseguida por las montoneras del caudillo Piérola "por el pecado de mezclarnos en política" y ejercer "el derecho que existe de pensar y de expresar el pensamiento", según escribe en "Boreales" (Matto 1902, 23) ${ }^{8}$. Como en el relato de Maipina, este viaje es el resultado de un conflicto, aunque no de índole personal y económico, sino político y cultural. Matto aspiraba a ingresar en el campo de las letras y de la contienda política en igualdad de condiciones que sus compañeros de oficio, lo que provocó diversos episodios de violencia física y simbólica contra ella, el primero en 1889, luego de publicar Aves sin nido, el segundo en 1890 por la publicación de "Magdala", y finalmente el más grave, en 1895 por la intensificación de su protagonismo cultural y político'. Por ello, "permanecer en el Perú era algo mas que difícil", como escribe al llegar a Chile. Pero antes de que esta herida produzca pesar e impotencia en el sujeto narrador, surge "la inspiración del espíritu" que la impele a viajar a "playa extranjera, no para ir a llorar la derrota, sino para vigorizarnos en la triple escuela del trabajo, de los viajes y del patriotismo"(65). Cuando llega a Buenos Aires tres semanas más tarde habiendo cruzado la cordillera por

\footnotetext{
"Boreales" es la primera parte del libro Boreales, miniaturas y porcelanas que incluye tres acápites: 'Perú: Narraciones históricas', que relata los episodios de violencia que sufre en Lima y que la inducirán a partir; 'En Chile', que incluye el viaje a bordo del "Maipo" por las costas chilenas, la llegada a Valparaíso y el viaje a Santiago; y 'En Argentina', que narra el viaje desde Mendoza hasta Buenos Aires.

La publicación de Aves sin nido y un año más tarde del cuento de Coelho Netto desencadenaron la excomunión por decreto del Arzobispado de Lima y la censura a El Perú Ilustrado donde este fue publicado, además de un auto de fe en Arequipa donde se quemaron los ejemplares de EPI, una denuncia de la fiscalía, todo lo cual desembocó en la renuncia de Matto a la dirección del periódico en julio de 1991. Esto sin mencionar las sátiras rabiosas como las de Juan de Arona llamándola "marimacho que escribe mamarrachos", entre otras diatribas. Para detalles de estos incidentes, ver Denegri 2004, 172-176.
} 
la misma ruta por la que veinte años antes viajara Maipina, se ha afirmado en su misión de "buscarme el pan que no podíamos hallar en aquel suelo cargado de venganzas, de atropellos y de cuanto innoble puede producir la comandita del clericalismo con el pierolismo" (24). Resulta de particular interés el contraste que resulta de la representación del sujeto narrador en el relato de Maipina y el de Clorinda. Mientras que esta se muestra en control de horarios, hoteles, transporte, precios, salud y emociones y se construye desde "la voz de la razón" (99), Maipina aparece acechada permanentemente por la duda, el miedo, el frío, la enfermedad, las incertidumbres y la impotencia para asegurarse caballos o alojamientos adecuados. Si la narración del viaje en "Boreales" es apurada, eficaz y con datos precisos de nombres, fechas e itinerarios, el de Mis vicisitudes es pausada, incierta e imprecisa, y si Clorinda solo se detiene para admirar los prodigios de la tecnología moderna o para registrar sus contactos con "lo más notable" de la intelectualidad (86), Maipina lo hará constantemente para registrar detalles del paisaje y de la conversación menuda con los compañeros de ruta. Si el sujeto narrador en este inspira compasión y ternura en sus interlocutores, en el otro inspira admiración y respeto por la distinguida fama que la precede.

El tópico del trabajo es recurrente en este relato, como lo es en sus cartas a Palma y en sus editoriales de El Perú Ilustrado y Los Andes; por ello el haber perdido la principal fuente de vida que representaba para ella su imprenta constituye la herida que más le duele (57). De sus cartas a Palma escritas en Arequipa a partir de 1883 cuando era una mujer ya sola, forastera, viuda y rayando en la pobreza, sabemos que pasaba largas horas trabajando en el periódico La Bolsa a cambio de "sueldos miserables" pagados tarde, mal o nunca. Escribe por ello que conoce de cerca "lo que es ser mujer en el Perú con voluntad de trabajo, sin poderlo conseguir"" . Al mudarse a Lima en 1886 espera mayor reconocimiento que en Arequipa, pero a pesar de tocar muchas puertas tendrá que esperar todavía tres años para tener un trabajo regular en la dirección del prestigioso El Perú Ilustrado en 1889, al que sin embargo tendrá que renunciar bajo presión apenas dos años más tarde.

Es acaso este conocimiento particular de "lo que es ser mujer en el Perú" lo que permite que el motivo de la huida en su texto de viaje se convierta, a medida que avanza el relato, en oportunidad de trabajo para ganarse no solo el pan, sino también la independencia que viene con el anhelado estatus de 
"profesional". Para ello construye un sujeto narrativo que desde un inicio muestra la convicción de que apropiarse de $s u$ lugar en el espacio público de las letras, aun si "en playa extranjera" y contra viento y marea, será su norte. Una de las estrategias que despliega para lograrlo es la de dejar constancia de cómo, desde Arica hasta Valparaíso, y desde Santiago hasta Buenos Aires, su labor de escritora y editorialista le ofrece frutos materiales y simbólicos. Como ilustración del primero, el dolor de llegar a Pisagua, que hasta hacía apenas quince años había sido territorio peruano, es motivo para que la viajera vuelva a condenar con indignación a Piérola y "de paso", recomendar la lectura de la Historia del Perú de Markham, publicada en su integridad por la imprenta de su propiedad, La Equitativa, que compara con la de Gil, llena esta de "vergonzosas mutilaciones referentes al señor Piérola", a quien ella culpa de la derrota (69). De los frutos simbólicos de su labor abundan ejemplos; en Arica, por ejemplo, se consigna el gesto de Rómulo Cúneo Vidal, intelectual peruano de prestigio, de ir a saludarla a bordo para charlar "sobre novedades literarias y bibliófilas" (68); en Iquique registra la "galante acogida" con la que es recibida cuando visita las oficinas de los periódicos (72); en Valparaíso escribe con deleite acerca de la comisión de periodistas que la recibe (76) y de los periódicos que la anuncian como "distinguida literata" peruana (82); finalmente en Santiago constata su buena reputación al ser bien recibida por sus intelectuales y figuras públicas, y al leer el lenguaje celebratorio que le prodigan los periódicos por su ilustración y sus "notables escritos". El cuidadoso registro de estos elogios a su persona en el relato no producen sin embargo el efecto de alarde comentado páginas arriba para el caso de textos de autoría masculina, sino mas bien el de un necesario anclaje, acaso desafiante, de la subjetividad autorial femenina en el espacio público de las letras en un contexto en el que muchos intelectuales tanto del catolicismo militante como de las filas liberales laicistas, veían el ingreso de las mujeres en la literatura como amenazadora señal de una potencial y desestabilizadora masificación del campo cultural que hasta entonces había sido coto exclusivo de la elite masculina ${ }^{11}$. Sugiere María Vicens que a su llegada a Buenos Aires, Matto se reinventa, reorganiza su agenda, y refuerza

11 En Bulla y buchiplumeo. Masificación cultural y recepción letrada en la Venezuela gomecista, Raquel Rivas Rojas estudia el modo en que la enunciación de un "nosotros" en la prensa caraqueña gomecista diseña nuevos sujetos que negocian sus roles y legitiman sus espacios en los imaginarios culturales. Aunque su enfoque es un periodo posterior (19251935) al nuestro y un sujeto popular antes que femenino, encuentro muy sugerentes sus 
su mapa de contactos con miras a profesionalizarse para salir del estado de precariedad económica en el que la había sumido el exilio (Vicens 2015). Me gustaría sugerir que es quizás en la experiencia misma de la escritura del viaje donde se habría comenzado a gestar esta reinvención de su persona como respuesta al antagonismo de género vivido en carne propia precisamente "por ser mujer en el Perú" y en situación de franca desventaja en sus aspiraciones laborales con respecto de sus pares varones.

Necesario es recordar que las experiencias de viaje consignadas en Mis impresiones y mis vicisitudes y en "Boreales" representan periodos separados por la guerra del Pacífico (1879-1883) y por la sorda lucha que en las décadas del 80 y 90 protagonizarán las mujeres para posicionarse como mujeres de letras. El balance de estas luchas es algunas victorias y muchas derrotas, pero sobre todo la eclosión de nuevas identidades de género, como la que Matto construye y consolida en "Boreales". El claro contraste entre las subjetividades femeninas construidas en uno y otro relato no debe entenderse por tanto solo en términos de las diferencias y singularidades cifradas en las personalidades de cada una de las viajeras, sino también en términos del horizonte ideológico de dos generaciones que marcan un antes y un después en las relaciones de género que atraviesan el campo literario. Sirva de ilustración para el caso peruano, el espíritu que distingue a las famosas veladas literarias limeñas de la preguerra en los salones de Gorriti y aquel otro de las veladas de Matto de la posguerra. Si bien es cierto que en ambas se privilegian temas de literatura y educación femeninas, en las veladas de Gorriti es el americanismo fraternal en clave romántica el que marca el tono de los discursos, mientras que en las de Matto es sobre todo la reconstrucción de una identidad nacional en cuyo seno se libran diversos conflictos la que gravitará con mayor fuerza. Si en las de Gorriti el conflicto social y político es una tema silenciado, en las de Matto abundan los relatos y dramas de tópicos que aluden a la violencia como síntoma de los antagonismos sociales desatados por la guerra, entre ellos, el de raza, género, clase y regionalismo. Las veladas de Matto de 18871888 se configuraron así como un espacio donde los intelectuales criollos debatieron por primera vez en el país sobre todo dos temas que aunque silenciados por los grupos de poder, eran constitutivos del conflicto de la sociedad peruana de entonces: el estatus del indio sin tierras y el de la mujer sin trabajo (Denegri 2017).

planteamientos para pensar el problema de la profesionalización de la mujer de letras en el campo cultural de fin de siglo latinoamericano. 
Uno de los rasgos mas saltantes de la mirada desde la que el sujeto narrativo relata sus aventuras y desventuras en Boreales, es la de su firme anclaje en el espacio profesional de las letras, es decir, en el espacio de conocimiento y formación especializada que comparte con una comunidad de escritores y "obreras del pensamiento", como ella misma las llama en un ensayo de esta misma época, cuya igualdad a "los soldados del pensamiento" de la confraternidad intelectual latinoamericana es asumida (Matto 76). Así pues, a pesar de las dramáticas y dolorosas circunstancias de este viaje de exilio que será definitivo, porque no volverá mas a su país, y a pesar de la herida abierta que representa el exilio, el sujeto narrativo registra con creciente intensidad, a medida que progresa el relato, los esfuerzos desplegados para ampliar su red de contactos periodísticos y literarios, y las escenas de interlocución con intelectuales distinguidos que la fortalecen en su deseo de consolidarse como profesional de las letras. Si De la Barra se retrata dialogando con una larga serie de anónimos interlocutores, entre los que destacan esclavas, damas de compañía, niños, cocheros, ovejeros, taberneras, arrieros, dueñas de hospedaje y viajeras con las que comparte diversos tramos del camino, Matto lo hará con personajes de la alta cultura argentina, peruana y chilena, entre ellos, el escritor argentino Eduardo Wilde, el chileno Pedro Pablo Figueroa, el diputado Blest Gana y el poeta peruano Domingo de Vivero (73). Señalan Arcos y Salomone que con la apertura a la palabra ajena, Maipina transforma el modelo discursivo monológico clásico masculino y le confiere porosidad a esta representación femenina de la alteridad (Arcos y Salomone 24), observación acertada y tan relevante para el relato de Maipina, como para los de Tristán y Gorriti, pero que habría que matizar para los de Matto y Mansilla, tomando en cuenta los contextos culturales y políticos tan distintos y ya señalados para el caso de Matto.

El firme posicionamiento de Matto como profesional de las letras en plena actividad a pesar del golpe recibido le confiere además el poder de asumir en su relato de huida de la patria, la representación de una primera generación de mujeres ilustradas en el Perú que fue tan aclamada en la en la década del 70, como atacada y vilipendiada después de la guerra. Ya para 1895, el año de partida de Matto, habiéndose consolidado la consigna de González Prada en aras de una literatura "viril" que "arroje ideas como los titanes fulminan peñascos" (González Prada 2003) y habiéndose convocado para ello a "lejiones de hombres" que reemplazaran a las "procesiones de resucitadas plañideras" (Gonzáles Prada 2003), quedan condenados al ostracismo no solo los románticos peruanos, sino también el grupo de escritoras que habían logrado saltar a la palestra pública gracias a las veladas 
literarias de Gorriti. Por estas razones encuentro muy sugerente la lectura de Arturo Ruiz quien, siguiendo a Pollak, propone que "Boreales" funcionaría como "el índice de un deseo de encuadrar la memoria subterránea" en la que se habría convertido ya para entonces la literatura de autoría femenina peruana tras el auge de la "literatura de propaganda y ataque" promovida por Prada (artículo en preparación). Al imponérseles, como escribe Ruiz, la doble opción del "silencio como consecuencia del declive de la literatura romántica que favorecía su participación en la esfera letrada, o la sanción crítica por arrogarse atributos escriturales 'masculinos"”, sugiero que esta primera generación de ilustradas peruanas se encuentra, con otra modalidad del nudo gordiano de nuestro título. Si la destrucción de la imprenta de Matto constituye, como lo sugiere Ruiz, una metáfora de la destrucción de la voz femenina letrada en la posguerra que respondió a los llamamientos de Prada con novelas de denuncia "viriles" como Aves sin nido y Herencia, y con periódicos como Los Andes, "Boreales" se constituye como el espacio para encuadrar la memoria subterránea que habría producido este nudo de imposible solución con el que se encuentran Matto y sus compañeras de oficio en el proceso de transformación de sus discursos creativos. Las condiciones favorables que ofrecen Chile y Argentina para la inclusión de la ciudadanía femenina constituyen un aliciente para su nuevo proyecto. La tensión que la visita a Iquique, ciudad que había pertenecido al Perú pero que era entonces chilena, produce en el sujeto narrador es ilustrativa, porque si por un lado se revive la pérdida de la guerra, por el otro se despierta la admiración hacia ese país donde en los tranvías y las oficinas "la mujer es protegida en su trabajo con preferencia al varón" (71). Dicha situación constituye en realidad una suerte de anuncio acerca de las condiciones favorables que en este tema habrá de encontrar en su país de adopción, y que resultarán propicias para que dicha memoria hasta entonces subterránea emerja a la superficie del espacio público como una memoria ahora encuadrada en la historia del feminismo continental que despuntaba como promesa en el Buenos Aires que acogió a Clorinda desde su llegada en 1895 hasta su muerte en 1909.

EL OLVIDO DE LA HERIDA. RECUERDOS DE VIAJE, DE EDUARDA MANSILLA

Eduarda Mansilla abandona a su familia en Paris para regresar a Buenos Aires en 1879. En su ciudad natal se instala sola tras diecinueve años de 
vivir y viajar por Europa y Estados Unidos como esposa de diplomático, para reorganizar su vida y dedicarla a la literatura, aun si de ello no da cuenta en su relato Recuerdos de viaje, y aun si luego justificará su decisión de abandonar Paris apelando a la salud de su madre y silenciando las razones de fondo que la habrían llevado a partir. El relato que desde Buenos Aires escribe acerca de su estancia en Washington durante la guerra de secesión, cuando todavía era "señora del" plenipotenciario argentino, es fruto de esta nueva etapa de su vida como mujer separada y dedicada a tiempo completo a las letras. Relato singular, como lo señala Spicer Escalante, por la particular apropiación de las causeries creadas por su hermano Lucio; pero también porque en contraste con los alardes del Entre-nos de Lucio, lo que produce este libro de causeries son silencios y olvidos.

Propongo leer Recuerdos de viaje como un trabajo de construcción de la memoria desde un presente en el que Eduarda ya no está en Washington sino en Buenos Aires, tampoco tiene veintisiete sino cuarenta y siete años, y ha desplazado su centro desde el corazón de la familia para quedar flotando, no sin cierto desasosiego, en sus márgenes. No solo porque naturalmente han pasado los años, sino porque ella ha optado por cortar con ese pasado, abandonando a la familia e instalándose en Buenos Aires para reinventarse como mujer de letras a tiempo completo ${ }^{12}$. Es en los significados de ese corte complejo y doloroso en el que propongo hacer una indagación en esta sección. Para ese trabajo de memoria que emprende Mansilla en Recuerdos de viaje, ella debe olvidar, o censurar, ciertas secuencias conflictivas de su vida personal, que a su vez le permitan recordar otras secuencias públicas de prestigio. Será entonces gracias a esta operación de edición de la memoria que será capaz de construir desde el incómodo presente en el que vive, una imagen del pasado que no suscite muchas preguntas. Propongo que el olvido que realiza en la escritura del texto se centra en su esposo: Manuel García, diplomático cuyo cargo de Secretario de la Legación Argentina en Washington es el motivo del viaje que ella y sus hijos emprenden, y que este olvido de

12 Las razones que las críticas y estudiosas proponen del retorno a Buenos Aires son diversas. Spicer-Escalante (2006), Szumurk (2007), Chikiar-Bauer (2013), Néspolo (2015), Lojo (2011) y Miseres (2017) coinciden en señalar su deseo de dedicarse enteramente a escribir; aunque consideran algunas también el deseo de reencuentro con su madre, y otras, siguiendo la versión que de este episodio ofrece Juana Manuela Gorriti en su correspondencia con Palma, se detienen en la versión de un discreto romance extramarital de Eduarda que sin embargo habría terminado disolviendo definitivamente su matrimonio. 
Manuel se configura en un ruidoso fantasma cuya presencia recorre el relato de principio a fin, precisamente desde la ausencia. Porque a pesar de que solo dos veces se le menciona, su presencia es la pieza central del sistema que echa a andar la escritura, al mismo tiempo que presiona desde sus orillas y desde sus vacíos, ya sea en los paseos, en los conciertos, los viajes, las visitas a los museos, el teatro, la ópera, los restaurantes, las ceremonias del colegio de sus hijos, los salones de sociedad, o los hoteles adonde esta viajera distinguida llega sola, siempre sola, y cuyo recuerdo narra consistentemente en una primera persona en deliberado y extraño singular a lo largo de todo el relato. La presencia fantasmagórica del esposo presiona no solo en los episodios de ocio mencionados, sino que, lo que resulta más enigmático, también en las ceremonias oficiales en las que desfila el cuerpo diplomático en pleno frente al presidente, y en los desfiles militares, en las recepciones y en los bailes diplomáticos, donde Eduarda Mansilla brilla por su solitaria presencia y Manuel García por su elocuente ausencia.

Este ubicuo fantasma se anuncia ya desde el primer capítulo, cuando recién llegada a Nueva York la viajera narradora debe hacerse cargo ella sola de los trámites de inmigración en medio de las dificultades con una lengua cuyas inflexiones americanas no comprende, a lo que se suma el caos propio del puerto, y las legiones de cocheros "groseros, feos, mal entrazados, con enormes látigos que blandían despiadados, furiosos, sobre las indefensas cabezas de los viajeros" (10). La escena inaugural llega a su paroxismo cuando uno de estos calibanes de pesadilla encarnado en cochero sube con brusco ademán a uno de los pequeños sobre sus hombros, acto que produce tal horror en la madre que "pierde el sentido" y cae desmayada (10). Esta llegada a Nueva York, conspicua por la soledad de la viajera con sus pequeños hijos, se reproduce en otros viajes al interior de Estados Unidos. A Filadelfia, a Baltimore, a Pensilvania, a Canadá, a las cataratas del Niágara, Eduarda viaja sola o acompañada por chaperones de la legación argentina que hacen las veces de sustitutos de su esposo, entre ellos el doctor Acosta (XIX), el Molinita, decano del cuerpo diplomático argentino, (100), el cónsul de Argentina, Eduardo Davison (53), y el chileno Santiago Arcos. Son ellos y nunca su esposo los llamados a sacarla de los apuros y de los trámites propios del viaje y de la llegada a los hoteles de las grandes ciudades a esta madre inexperta que se autorretrata viajando siempre sola con sus hijos (101). Aun al baile en honor de los Príncipes de Orleans llega ella sola, "expuesta a las miradas de la mosquetería" y aterrada al subir las escaleras de la "espléndida mansión" con la idea de poder caerse con el traje voluminoso y complicado 
de baile, sin un brazo que la ayude ( p.106). ¿Dónde estaba Manuel García en estas fechas de gran importancia para un diplomático? ¿Dónde estaba el pater familiae mientras su esposa y sus hijos vivían la experiencia del viaje por Estados Unidos? De este misterio el texto no da cuenta. Solo dos veces lo alude y de manera indirecta por su título oficial, "Secretario de la legación" (50), nunca por su nombre, distancia que se intensifica con el inglés de la segunda referencia cuando en conversación con sus amigas, las Moss, se refiere a García como el "handsome Secretary" (79), o cuando en una ocasión se refiere irónicamente a sí misma como"una simple Secretaria de Legación de una República de nada" (57).

Lo que sin embargo sí leemos en Recuerdos de viaje como contrapeso al ruidoso silenciamiento del conflicto conyugal, es una cautelosa reflexión acerca del matrimonio y el divorcio a propósito de usos y costumbres estadounidenses que resultan reñidos con los argentinos. Mansilla considera los dos tipos de matrimonio entonces vigentes, el matrimonio por amor y el de por conveniencia, pronunciándose a favor del último. Esgrime para ello el argumento de "la inestabilidad de las cosas humanas, su fragilidad transitoria", que en "las uniones que consultan los hábitos, la educación y aun el temperamento de los cónyuges acaso ese género de conveniencias resultara ser una base sólida y estable, para la consolidación de la familia futura" (p.86). Bastante se ha escrito acerca de lo mucho que dio a hablar el matrimonio de Eduarda y Manuel en su tiempo, y del imaginario local que hablaba de un enlace a lo Romeo y Julieta por tratarse de familias prominentes en posiciones políticas de intenso antagonismo (Chikiar Bauer 33, Szumurk 336, Néspolo 12). Se trataba entonces de un enlace glamoroso de amor romántico contra viento y marea que sin embargo luego el tiempo y la convivencia acaso fueron deshaciendo, cumpliéndose quién sabe que secretos pronósticos que la joven Eduarda no quiso naturalmente acatar y a los que la Eduarda madura tal vez aludía tangencialmente en esta reflexión. Podríamos leer del mismo modo sus elípticas palabras acerca del divorcio que ya entonces era legal en Estados Unidos. "No tengo al respecto una opinión hecha", escribe, para luego, con una rápida vuelta de tuerca darle un nuevo sentido a la duda. "La familia, tal cual existe hoy", continúa, "habrá de pasar, a mi sentir, por grandes modificaciones que encaminen y dirijan el espíritu de los futuros legisladores para cortar este moderno nudo gordiano" (p. 86). Ese complicado nudo gordiano hecho con los hilos de la libertad individual y los deberes de familia que Mansilla imagina como un rompecabezas para los legisladores del futuro es el mismo nudo que ella misma ya había 
cortado para echar a andar su proyecto de dedicarse a la literatura en su tierra natal. No es necesario elaborar acerca del sentido que estas palabras sugieren en cuanto a la naturaleza de estas modificaciones, pero sí señalar la complejidad del tema para una escritora que proclamaba las ventajas del modelo tradicional del matrimonio y la división de los espacios según el género, donde el papel de la mujer era desempeñarse en el espacio privado al lado de su esposo para de ese modo "influenciarlo", y que cuestionaba los "sueños de emancipación política" de las mujeres de su época. "¿Qué ganarían las americanas con emanciparse?" se preguntaba. La respuesta era lapidaria, "Mas bien perderían y bien los saben" (72). Si a la presencia fantasmagórica del esposo en este relato escrito desde los trabajos propios de la memoria y de la modalidad "diarística-autobiográfica" le sumamos el silencio frente al dramático quiebre conyugal en su vida, y las contradicciones frente al tema de la emancipación femenina en su discurso, podríamos pensar que se trata de un silencio constitutivo de una particular autoría femenina de viaje que se construye olvidando la herida que motivó la partida.

Como señala Spicer Escalante, la autoría de este relato de viajes de Eduarda es contestaría y contra-discursiva porque se trata de su propia respuesta a las celebradas crónicas de viaje de su hermano. Como tal involucra la creación de "una voz "viajera" relacionada con la causerie" que es la marca particular del Entre Nos de Lucio, pero con una diferencia genérica suficiente para indicarnos que Eduarda estaría escribiendo sus Recuerdos en franca competencia con él. Por su lado, Batticuore destaca en la relación de Eduarda con su hermano la tensión que habría entre la competencia y la complicidad y el modo en que al publicar Lucio Viaje a ranqueles y Eduarda Pablo ou la vie dans les Pampas en el mismo periódico, la pampa se estaría continuando de un hermano a otro, pero que en la traducción que hace Lucio de Pablo, habría en cambio desautorización e interceptación (Batticuore 176). Es en este contexto que se ha leído la inclusión en Recuerdos de viaje de la esfera doméstica yankee, emblematizada en la descripción de los dormitorios y la ropa de cama, es decir, como espacio que ella incluye en su relato para demostrar su ventaja de género sobre Lucio y los otros varones de su estirpe, quienes no tendrían acceso a estos espacios mientras que ella sí. Considero sin embargo que el hecho de que el sujeto narrativo no incluya en su relato ninguna descripción de sus propios ambientes privados o domésticos, es síntoma de su deseo de des-esencializar su condición femenino doméstica y de singularizarse como viajera a secas. 'Viajera distinguida' que pasea sola, viaja sola, se relaciona sola, y elije olvidarse de su condición de 'esposa de'. 
La primera persona singular se usa también cuando recuerda la dirección de su casa en Washington y escribe "Yo he vivido en la calle Y" (61), pero no da más detalles de su residencia.

Así pues, creo que lejos de aceptar complaciente su condición de segundo sexo, o de esposa de diplomático que viaja como acompañante con su casa a cuestas (Frederick 1994), lo que le interesa a Mansilla es precisamente reinventarse en el espacio narrativo como profesional de las letras, libre de ataduras conyugales y domésticas. Es en este contexto que habría que leer su interés por el lugar que ocupan las mujeres en el mercado laboral estadounidense. "La mujer americana", escribe, "practica la libertad individual como ninguna otra en el mundo, y parece poseer gran dosis de self-reliance (confianza en sí mismo)" (70). Pero es su visibilidad en el periodismo lo que más la entusiasma. "En el periodismo", continúa, "véseles ocupando puestos que nada de anti femenino tienen. Los periódicos en Estados Unidos cuentan con una falange de encargadas de los artículos del Domingo, de esa literatura sencilla y sana que debe servir de alimento intelectual a los habitantes de la Unión, en el día consagrado a la meditación" (72). El tema laboral, en el que el periodismo ocupa el puesto principal, tan importante como el de la educación para las escritoras del último tercio del XIX, recorre estas páginas con la intensidad que vimos en los textos de Matto y De la Barra. "En ello, además", escribe Mansilla, "las mujeres tienen un medio honrado e intelectual para ganarse la vida: y se emancipan así de la cruel servidumbre de la aguja, servidumbre terrible desde la invención de las máquinas de coser. Más tarde debía aparecer la mujer empleado ya en el Correo ya en el Ministerio" (73), observaciones que resuenan con las palabras de Matto en Iquique.

Concluyo proponiendo que, tal como intento demostrarlo en esta sección dedicada a Mansilla, es con el fin de reinventarse que Eduarda adecúa el recuerdo de la experiencia pasada en su escritura, tarea que le exige emborronar los nombres, lenguajes y tramas privadas que amenazaron con trabar sus propios dones e inclinaciones, tal como escribiera Maipina una década antes en la advertencia a sus lectoras argentinas. Recuerdos de viaje constituye así el viraje simbólico por el que opta Eduarda en su vida y en su escritura para recuperar la agencia que habría perdido en su condición de viajera con su casa a cuestas. La ruta que eligió fue un desafío mayor porque supuso el ensayo de nuevas identidades de género que en su caso particular exigía como tributo el doloroso desprendimiento del núcleo familiar. En este corte del nudo gordiano, a diferencia de aquel realizado por Alejandro, no es solo el limpio tajo de espada lo que interesa, sino más bien el trabajo de 
paciente sutura al que el sujeto femenino escindido debe abocarse después, trabajo que implica silenciar selectivamente la memoria para apenas sugerir, mas no exponer, el conflicto. Si Maipina insta a sus lectoras argentinas a reapropiarse de sus talentos perdidos, y Matto a "buscarse el pan con el sudor de su frente" como modos de suturar la herida, el caso de Eduarda Mansilla parece mas complejo y enmarañado, tal vez por la familiaridad y cercanía con que el conflicto resuena en la experiencia contemporánea de muchas de sus lectoras. Así pues, mientras que el viaje de las mujeres de letras considerado a partir de estos tres relatos fue desencadenado por fuerzas y constelaciones de afecto disruptivas que amenazaban con disolver vínculos sociales en el entorno familiar y laboral, el de los varones, como lo vimos al inicio, era motivado por fuerzas asociativas que promovían, reforzaban y consolidaban esos mismos lazos sociales con el entorno. El tema de "la herida", ocasionado en De la Barra por la pobreza y el abandono, en Matto por la violencia del trabajo negado, la propiedad destruida y la voz censurada y en Mansilla por la arbitraria elección entre familia y vocación, se moviliza en estas narrativas dentro de diversas estrategias que incluyen su esencialización, su historización o su silenciamiento. Sugiero por ello que las políticas emancipatorias de educación y trabajo femeninos que de diversos modos promovieron estas tres escritoras en sus relatos de viaje, constituyen una respuesta coral frente al reconocimiento de la herida de género que fue la que en primer lugar provocó este tipo de viaje sin pasaje de retorno.

\section{BIBLIOGRAFÍA}

Ahmed, Sarah. The Cultural Politics of Emotions. New York: Routledge, 2004.

Alzate, Carolina. "Soledad Acosta de Samper. En la escena política de la escritura". Redes, alianzas y afinidades. Mujeres y escritura en América Latina. Homenaje a Montserrat Ordoñez (1941-2011). Carolina Alzate y Darcie Doll (comp.). Bogotá y Santiago de Chile: Universidad de los Andes, Universidad de Chile, 2014. 19-43.

Arcos, Carol y Alicia Salomone. “Autoría, espiritualismo y educación femenina en el relato de viajes de Maipina de la Barra (1878)". Redes, alianzas y afinidades. Mujeres y escritura en América Latina. Homenaje a Montserrat Ordoñez (1941-2011). Carolina Alzate y Darcie Doll (comp.). Bogotá y Santiago de Chile: Universidad de los Andes, Universidad de Chile, 2014. 17-31.

Batticuore, Graciela. "Itinerarios culturales. Dos modelos de mujer intelectual en la Argentina del siglo XX”. Revista de Crítica Literaria Latinoamericana 43-44 (1996): 163-180. 
La mujer romántica. Lectoras, autoras y escritoras en la Argentina: 1830-1870. Buenos Aires: Edhasa, 2005.

Blest Gana, Alberto. De Nueva York al Niágara. Santiago: Imprenta Nacional, 1867.

Bustamante, Juan. Apuntes y observaciones civiles, politicas y religiosas con las noticias adquiridas en este segundo viaje a Europa. París: Imprenta de Lacrampe Son y Compañía, 1849.

Cane, Miguel. En viaje. Corbeil: Impr. de B. Renaudet, 1883.

Chikiar Bauer, Irene. Eduarda Mansilla. Entre-ellos. Una escritora argentina del siglo XIX. Buenos Aires: Biblos, 2013.

De la Barra, Maipina. Mis impresiones y mis vicisitudes en mi viaje a Europa pasando por el Estrecho de Magallanes y en mi excursión a Buenos Aires pasando por la Cordillera. Buenos Aires: Piqueras Cuspinera, 1878.

Denegri, Francesca. El abanico y la cigarrera. La primera generación de mujeres ilustradas en el Perú 1860 - 1895. Lima: Instituto de Estudios Peruanos, 2004

"Un aterrizaje de emergencia. Las veladas de Clorinda Matto De Turner en la Lima posbélica". Pensar en público. Las veladas literarias de Clorinda Matto De Turner. Evelyn Sotomayor. Ed. Lima: Biblioteca Nacional del Perú, 2017.

Escalante, J.P. "En su "calidad de viajera distinguida": La constitución de una voz femenina del viaje en Recuerdos de viaje (1882) de Eduarda Mansilla". Eduarda Mansilla de García. Recuerdos de viaje. Miami: Stockcero, 2006. vii-xxvi.

Frederick, Bonnie. "El viajero y la nómada: los recuerdos de viaje de Eduarda y Lucio Mansilla". Mujeres y cultura en la Argentina del siglo xix. Lea Fletcher. Ed. Buenos Aires: Feminaria Editora, 1994. 246-251.

González Echevarría, Roberto. Mito y archivo. Una teoría de la narrativa latinoamericana. México: Fondo de Cultura Económica, 2000.

González Prada, Manuel. “Conferencia en el Ateneo de Lima”. Recuperado de: http://evergreen. loyola.edu/tward/www/gp/libros/paginas/pajinas1.html. Revisado el 15 de junio de 2017.

Gorriti, Juana Manuela. "Peregrinaciones de una alma triste". Panoramas de la vida. Buenos Aires: Imprenta de Mayo, 1876.

Lojo, María Rosa. "Eduarda Mansilla: entre la "barbarie" yankee y la utopía de la mujer profesional”. Prólogo. Eduarda Mansilla. Recuerdos de viaje. Córdoba: Buena Vista Editores, 2011. 11-37.

Mansilla de García, Eduarda. Recuerdos de viaje. Miami: Stockcero, 2006.

Mansilla, Lucio. El excursionista del planeta. Escritos de viaje. Selección y prólogo de Sandra Contreras. Buenos Aires: Fondo de Cultura Económico, 2012.

Márquez, José Arnaldo. Recuerdos de viajes a los Estados Unidos del Norte 1857-1861. Lima: Imprenta del "Comercio" pop [sic] J. M. Monterola, 1862.

Masiello, Francine. Entre civilización y barbarie. Mujeres, nación y cultura literaria en la Argentina moderna. Buenos Aires: Beatriz Viterbo, 1997.

Matto de Turner, Clorinda. Boreales, Miniaturas y Porcelanas. Buenos Aires: Impr. de Juan A. Alsina, 1902. 
“Correspondencia con Ricardo Palma”. Biblioteca Nacional del Perú, 1883-93.

Miseres, V. Mujeres en tránsito: Viaje, identidad y escritura en Sudamérica (1830-1910). Chapel Hill: Department of Romance Studies. The University of North Carolina at Chapel Hill, 2017.

"Trabajo periodístico, género y emotividad: Clorinda Matto de Turner, directora de El Perú Ilustrado". Caiga jueves en domingo. Emociones en el Perú posbélico. Francesca Denegri. Ed.

Montaldo, Graciela. Ficciones culturales y fábulas de identidad en América Latina. Rosario: Beatriz Viterbo Editora, 1999.

Néspolo, Jimena. Prólogo: Creaciones (1883), Eduarda Mansilla. Edición, introducción y notas a cargo de Jimena Néspolo. Ediciones Académicas de Literatura Argentina. Siglos XIX y XX. Bs. As: Ediciones Corregidor, 2015.

Palma, Ricardo. Recuerdos de España: notas de viaje, esbozos, neologismos y americanismos. Buenos Aires: Impr., Lit. y Encuadernación de J. Peuser, 1897.

Soldán, Paz y Pedro Unanue. Memorias de un viajero peruano. Apuntes y recuerdos de Europa y Oriente 1859-1863. Lima: Biblioteca Nacional del Perú, 1971.

Pearce, Diane. "The Feminization of Poverty: Women, Work and Welfare". The Urban and Social Change Review. 11, 1 \& 2, (1978): 28-37.

Peluffo, Ana. Lágrimas andinas: sentimentalismo, género y virtud republicana en Clorinda Matto de Turner. Pittsburgh: Instituto Internacional de Literatura Iberoamericana, 2005. 68-76.

"La erotización de las lágrimas en Sab de Gertrudis Gómez de Avellaneda (18141873)". Redes, alianzas y afinidades. Mujeres y escritura en América Latina. Carolina Alzate y Darcie Doll. (comp.). Bogotá y Santiago de Chile: Universidad de los Andes, Universidad de Chile, 2014. 3-17.

Pérez Rosales, Vicente. Diario de un viaje a California. Santiago: Sociedad de Bibliófilos Chilenos, 1949.

Pollak, Michael. Memoria, olvido, silencio. La producción social de identidades frente a situaciones límite. La Plata: Ediciones Al margen, 2006.

Pratt, Mary Louise. Imperial Eyes: Travel Writing and Transculturation. Chicago: University of Chicago Press, 1996.

Rivas Rojas, Raquel. Bulla y buchiplumeo. Masificación cultural y recepción letrada en la Venezuela gomecista. Caracas: Editorial La Nave Va, 2002.

Ruiz Mautino, Arturo Florentino. "En nuestro naciente taller americano: Memoria subterránea y memoria oficial en Boreales de Clorinda Matto de Turner". Caiga jueves en domingo. La política cultural de las emociones en el Perú posbélico. Francesca Denegri. Ed. Lima: Fondo Editorial de la PUCP, 2017.

Sarmiento, Domingo Faustino: Viajes por Europa, África y América. Santiago: Imprenta de Julio Belin y cia., 1849, 1851.

Stevens, Evelyn P. "Marianismo: The Other Face of Machismo in Latin America". Female and Male in Latin America: Essays. Ann Pescatello. Ed. Pittsburgh: Pittsburgh University Press, 1973. 90-101.

Szurmuk, Mónica. “Geometrie de la memoire”. Sociocriticism. XXIX, 1 \& 2 (2014): 335-345. 
Miradas cruzadas: narrativas de viaje de mujeres en Argentina (1850-1930). México: Instituto Mora, 2007.

Tristán, Flora. Pérégrinations d'une paria. Paris: Arthur Bertrand, 1838.

Ulloa, Carla. "Crítica social y gestión cultural de una viajera sudamericana: Maipina de la Barra (1834-1904)". Tesis de Magister en Estudios Latinoamericanos. Universidad de Chile, 2012.

"Estudio preliminar". Mis impresiones y mis vicisitudes en mi viaje a Europa. Santiago: Editorial Cuarto Propio, 2013. 11-41.

Vicens, María. "Entre las vacaciones y el trabajo: sociabilidad y profesionalización en Viaje de recreo de Clorinda Matto de Turner". Decimonónica 12, No.2 (2015): 82-102.

Vicuña Mackena, Benjamín. Páginas de mi diario durante tres años de viaje 1853-1854-1855. Santiago de Chile: Imprenta del Ferrocarril, 1856.

Al galope, o sea, descripción geográfica y pintoresca de la comarca en que se halla situada la población-victoria y sus vecindades. Santiago: Imprenta Gutemberg, 1885.

Wilde, Eduardo. Viajes y observaciones. Buenos Aires: Impr. de Martín Biedma, 1892. 